\title{
Production of Secondary Metabolites in Plants under Abiotic Stress: An Overview
}

\author{
Indrajeet Kumar and Rajesh Kumar Sharma* \\ Department of Botany, Banaras Hindu University, Varanasi 221005, India \\ *Corresponding author: Rajesh Kumar Sharma, Department of Botany, Banaras Hindu University, Varanasi 221005, India
}

Submission: August 08, 2018; Published: November 26, 2018

\begin{abstract}
Now a day, plants, a source of natural antioxidants are facing various kinds of environmental stress during their growth and development. Under stress, plants have potential to synthesize several secondary metabolites to cope with the adverse effects of stress. In the present review paper, the information on the effects of different abiotic stresses on the levels of secondary metabolites in plants is summarised. The production of secondary metabolites in plants can be enhanced by modifying their environmental conditions.
\end{abstract}

Keywords: Plants; Environment; Stress; Secondary metabolites; Antioxidants

\section{Introduction}

Plants possess two types of metabolism called primary metabolism and secondary metabolism. Primary metabolism is related with the production of metabolites such as carbohydrates, amino acids, lipids etc., utilized by the plants for their growth and development. On other hand secondary metabolism is associated with the production of compounds involved in the protection of plants against various abiotic and biotic stresses. Secondary products are synthesized from primary metabolites. Secondary metabolites are important compounds for the human beings as they are sources for food additives, flavours, pharmaceuticals and industrially important pharmaceuticals [1,2], cosmetics, nutraceuticals, etc. Plant secondary metabolites such as morphine, codeine, cocaine, quinine etc., are commonly used in medicine. Alkaloids like, atropine, colchicine, phytostigminine, pilocarpine, reserpine and steroids like diosgenin, digoxin and digitoxin, flavonoids, phenolic, etc., are also the sources of different types of medicines [3].

Environmental stresses affect the metabolism of plants. Plants challenged with different types of abiotic and biotic stresses results into the reduction of different morphological characters such as height, leaf number, leaf area, number of branches, root volume, etc. [4] which ultimately leads to reduction of biomass production. There are different types of abiotic stress such as drought, low and high temperatures, salinity, alkalinity, ultraviolet radiation, ozone, metal ions, etc., which affect the metabolism of the plants. In normal metabolic conditions the synthesis of secondary plant products is often low as plant do not have any defence strategies due to lack of any stress. The synthesis of secondary metabolites is generally increasing when plants suffer with biotic and abiotic stresses. Accumulation of phenylpropenoids and phenolic compounds were found higher during stress condition in plants $[5,6]$. The concentrations of various secondary plant products are strongly dependent on the growing conditions and physiology through altering the metabolic pathways responsible for the accumulation of the related natural products [4]. The expression levels of certain genes governing the production of such compounds have also been shown to be increased in response to various abiotic stresses [7]. In this review, we have summarized the information about the effects of different abiotic stresses on the synthesis of secondary metabolites in plants.

\section{Responses of Plants to Abiotic Stresses}

Plant have potential to adopt some strategies to neutralize the effects of various abiotic stresses such as high and low temperature, salinity, alkalinity, UV, heavy metals, drought etc. The normal metabolism of plants got disturbed under stressed into decreased in growth and productivity and triggered a series of molecular, biochemical, physiological and morphological changes in plants. A stress response is induced when plants recognized the stress at the cellular level. During drought, plants might have tended to decrease the leaf area, to reduce the water loss through respiration, promote the leaf abscission, extend their root, etc., which is regulated by a combination of plant hormones. When plant suffer with oxidative stress, they synthesize the various secondary compounds and increases the level of different endogenous enzymes such as superoxide dismutase (SOD), catalase, (CAT), ascorbate peroxidase (APX), guaiacol peroxidase (GPX), and glutathione reductase (GR) and non-enzymatic antioxidants like ascorbate (AsA), glutathione (GSH), to reduce the effect of reactive oxygen species (ROS) produced in various stresses. Secondary metabolites are involved in protective functions in response to both biotic and abiotic stress 
conditions. Formation of phenyl amides and dramatic accumulation of polyamines in bean and tobacco under the influence of abiotic stresses were reported and suggested antioxidant role of these secondary metabolites by Edreva et al. [8]. Similarly, anthocyanin accumulation is stimulated by various environmental stresses, such as UV, blue light, high intensity light, wounding, pathogen attack, drought, sugar and nutrient deficiency [9].

\section{Effects of Abiotic Stresses on Synthesis of Secondary products}

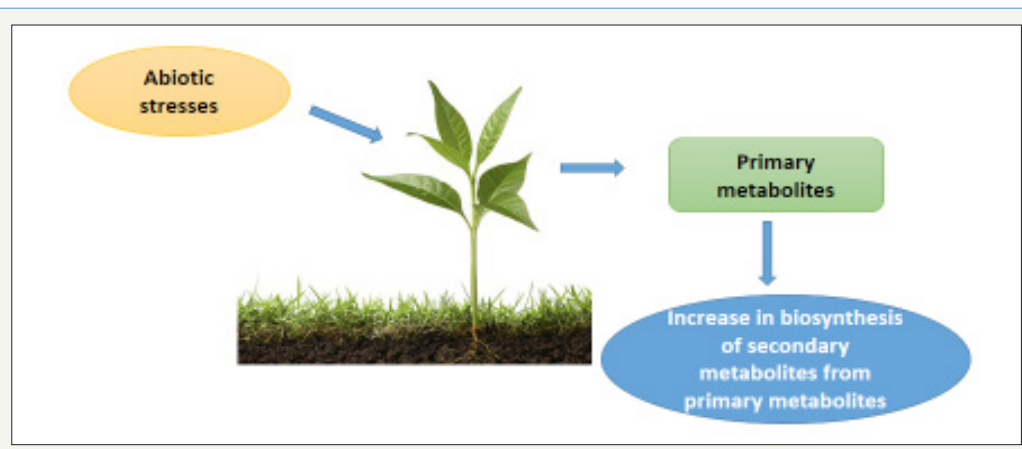

Figure 1: Effects of abiotic stress on synthesis of secondary metabolites.

Under the stress condition, the primary metabolisms of plant get decline due to unfavourable condition created by different environmental factors. Plants under stress reduce the effect of different abiotic as well as biotic stresses by the synthesizing the more secondary metabolites than normal conditions. These secondary products are biosynthesized from the products of primary metabolisms such as carbohydrates, lipid, and amino acids (Figure 1).

\section{Effect of Drought}

Drought is one of the most significant abiotic stresses which have adverse effect on growth and development of plants [10]. Drought stress occurs when the available water in the soil is low to some critical levels for the plants. Drought causes huge damage to the physiological machinery of the plants resulting in degradation of morphological topology, anatomical structure and biochemical activity i.e. enzyme activity, protein content, sugar content, etc. Drought often causes oxidative stress and was reported to show increase in the amounts of flavonoids and phenolic acids in willow leaves [11]. Morphine content in Papaver somniferum [12], glucocides content in [13] was found increased under water deficit condition as compared to normal. Total phenolic, total flavonoid, anthocyanin and polyphenolic compounds, which promoted the antioxidant capacities of Chrysanthemum sp was found increasing during drought condition [14]. The content of anthocyanin, flavonoid increases during the water stress and these compounds have protective role during drought condition in Pisum sativum [15]. In drought condition saponin content was found to be lower in Chenopodium quinoa [16] (Table 1).

Table 1: Effects of some abiotic stresses on synthesis of secondary metabolites in plants.

\begin{tabular}{|c|c|c|}
\hline Abiotic Stress/Plants & Secondary Metabolites & Reference \\
\hline \multicolumn{3}{|c|}{ Drought } \\
\hline Pisum sativum & Flavonoids (45\%), anthocyanins & [15] \\
\hline Labisia pumila & Total phenols (50\%) & [17] \\
\hline Salvia officinalis & Monoterpenes, essential oils ( 2 to 6 fold) & {$[18,19]$} \\
\hline Papaver somniferum & Morphin & [12] \\
\hline Chrysanthemumsp & Flavonoids, phenolics, anthocyanin, and polyphenols & [14] \\
\hline \multicolumn{3}{|c|}{ Salinity } \\
\hline Carthamus tinctorius $L$ & $\begin{array}{l}\text { Proline (74\%), glycine betain (81\%), total phenolic contents (5 fold), total flavonoids (about } \\
2.5 \text { fold). }\end{array}$ & [20] \\
\hline Lycopersicon esculentum & Sorbitol & [21] \\
\hline Oryza sativa $L$ & polyamines & [22] \\
\hline \multicolumn{3}{|c|}{ Temperature } \\
\hline Pringlea antiscorbutica & Agmatine and putrescine & {$[23]$} \\
\hline Medicago sativa $L$. & Quercetin and kaempferol & {$[24]$} \\
\hline Crucifers & Carotenoids & {$[25]$} \\
\hline \multicolumn{3}{|c|}{ Light } \\
\hline
\end{tabular}




\begin{tabular}{|c|c|c|}
\hline Vanilla planifolia & Vanillin & {$[26]$} \\
\hline Zingiber officinale & Gingerol and zingiberene & {$[27]$} \\
\hline Hordeum vulgare & Flavonoids & {$[28]$} \\
\hline \multicolumn{2}{|c|}{ Metal ions } & {$[29]$} \\
\hline Brassica juncea & Oil content (35\%) & {$[30]$} \\
\hline Beta vulgaris & Betalaines & {$[31]$} \\
\hline Lepidium sativum & Lepidine & {$[32]$} \\
\hline Abelmoschus esculentus $L$. & Thiol, proline, total phenolics, ascorbic acid content & \\
\hline
\end{tabular}

\section{Effects of Heavy Metal}

Heavy metals are important to the plants as they are the major unit of various enzymes such as $\mathrm{Zn}$ in carbonic anhydrase, Mo and Fe in nitrogenase, $\mathrm{Cu}$ in superoxide dismutase, etc. Metals such as $\mathrm{Cr}, \mathrm{Cu}, \mathrm{Mn}$, and $\mathrm{Fe}$ can also directly generate oxidative injury via undergoing Haber-Weiss and Fenton reactions, which leads to the formation of ROS or oxygen free radicals' species in plants, resulting in cell homeostasis disruption, DNA strand breakage, defragmentation of proteins, or cell membrane and damage to photosynthetic pigments, which may trigger cell death. Plant adopts different mechanisms and synthesizes different secondary products to copup with the problems associated with heavy metals. It was noticed that the anthocyanin content in the leaf of lettuce (Lactuca sativa L.) was decline due to Ni stress [33]. According to Singh \& Sinha [29], cumulative accumulation of $\mathrm{Cr}, \mathrm{Fe}, \mathrm{Zn}$ and Mn increased oil production upto 35\% in Brassica juncea L plant. Betalains content in Beta vulgaris $\mathrm{L}$. plant is stimulated by $\mathrm{Cu}^{2+}$ [34]. According to Sharma et al. [32], thiol, proline, total phenolics, ascorbic acid content and peroxidase activity were found to be increased in Lady's Finger (Abelmoschus esculentus L.) with increasing in Cd concentration in soil (Table 1). To reduce the effect of oxidative stress, plants have defensive strategies to scavenge the free radicals. Plant cells have developed antioxidant defense mechanism which is comprises of different endogenous enzymatic antioxidants (SOD, CAT, APX, GPX, and GR) and non-enzymatic antioxidants ascorbate (AsA), glutathione (GSH), carotenoids, alkaloids, tocopherols, proline, and phenolic compounds i.e. flavonoids, tannins, and lignin) act as the scavengers of free radicals $[35,36]$.

\section{Effects of Salinity Stress}

Salinity is one of the important abiotic factors which reduce the growth and developments of the plants. Salinity in the plant cells causes ionic, osmotic, and oxidative stresses [3]. Synthesis of different osmolites like glycine betain, proline, sorbitol, mannitol, pinitol, and sucrose etc., is one of the important ways to resist in saline condition in plant. Golkar \& Taghizadeh [20] found that the secondary plant products i.e. proline, glycine betain, carotenoids, total phenolic contents, total flavonoids were increasing when salinity increases upto $200 \mathrm{mM} \mathrm{NaCl}$ concentration in Carthamus tinctorius L. plant. During salt stress, different secondary metabolite products such as sorbitol and jasmonic acid in Lycopersicon esculentum L. plant [21], sucrose and starch in Cenchrus pennisetiformis L. plant [37], polyamines in Oryza sativa L. plant [22] were reported to be increased (Table 1).

\section{Effects of Temperature}

Temperature regulates the growth and developmental processes of plants. Plant faces generally two types of stress with reference to temperature; high and low temperature. High temperature in plants adversely affects the normal metabolic processes which can induce premature leaf senescence, reduce the rate of photosynthesis and biomass production in plants. Low temperature in plants causes a series of abiotic stresses including osmotic injury, desiccation, oxidative stresses, etc [3]. Low and high temperature affect the biosynthetic process of different secondary metabolites to resist with that stress. In low temperature environment, plant metabolism leads to synthesis of cryoprotectant compounds like sugar alcohols (sorbitol, ribitol, inositol), soluble sugars (saccharose, raffinose, stachyose, trehalose), and low-molecular weight nitrogenous compounds (proline, glycine betaine) [38] to cop up with adverse effects of the low temperature stress. Cold stresses enhance the production of phenolic compounds (Table 1) [39]. Molmann et al. [24] reported that the concentrations of quercetin and kaempferol in Medicago sativa L. plant were higher at the warmer temperature and more putrescine content was observed under low temperature environment [40]. Hummel et al. [23] investigated that in low temperature there was an increase in levels of polyamines (agmatine and putrescine) and their levels could be a significant marker of chilling tolerance in seedlings of Pringlea antiscorbutica. Carotenoids contents in Brassicaceae family, including $\beta$-carotene, were found to be slightly decreased at high temperature [25].

\section{Effects of Light}

In plant metabolism, light play a significant role in production of secondary plant products. Light intensity can promote photosynthesis and enhance dry matter accumulation, whereas excessive irradiation will evoke photo-damage in plants and markedly influenced the plant growth and development. Light enhanced the biosynthesis of secondary metabolites including gingerol and zingiberene in culture of Zingiber officinale L. plant (Table 1) [27]. UV-B exposure increased in flavonoids content in barley [28] and polyamines in cucumber, flavonols in Norway spruce, Picea abies. Yu et al. [41] investigated that light enhanced the biosynthesis of terpenoid indole alkaloids in Catharanthus roseus L plants (Table 1 ). 


\section{Conclusion and Perspective}

Abiotic stresses negatively affect the plants growth and development through altering the biochemical and physiological processes such as photosynthesis, respiration, transpiration, etc. There are many abiotic stresses such as salinity, heavy metals, light, temperature, UV, etc., which induces the oxidative and osmotic stresses in which ROS are formed and damage the proteins, DNA, RNA, promote the lipid peroxidation and causes the cell death. Under various stresses plants produced a number of secondary products such as phenolics, flavonoids, terpenoides, anthocyanins, etc. which help them to maintain their physiology well. From the present overview it can be concluded that the production of secondary metabolites can be optimized in plant by exposing them to different kinds of stresses. Future researches should focus towards the enhancement of bioactive compounds in plants by using various physiological and biochemical approaches.

\section{References}

1. Ravishankar GA, Venkataraman LV (1990) Food applications of plant cell cultures. Curr Sci 57: 381-383.

2. Ravishankar GA, Rao SR (2000) Biotechnological production of phytopharmaceuticals. J Biochem Mol Biol Biophys 4: 73-102.

3. Ramakrishna A, Ravishankar GA (2011) Influence of abiotic stress signals on secondary metabolites in plants. Plant Signal Behav 6(11): 1720-1731

4. Pradhan, J, Sahoo SK, Lalotra S, Sarma RS (2017) Positive impact of abiotic stress on medicinal and aromatic plants. Int J Plant Sci 12(2): 309-313.

5. Dixon RA, Paiva N (1995) Stress-induced phenylpropanoid metabolism. Plant Cell 7: 1085-1097.

6. Chalker SL, Fnchigami LH (1989) The role of phenolic compounds in plant stress responses. In: Paul HL (Ed.), Low temperature stress physiology in crops. CRC Press Inc, Boca Raton, Florida, USA, p. 40.

7. Tuteja N, Mahajan S (2007) Further characterization of calcineurin B-like protein and its interacting partner CBL-interacting protein kinase from Pisum sativum. Plant Signal Behav 2(5): 358-361.

8. Edreva AM, Velikova V, Tsonev T (2000) Phenylamides in plants. Russ ] Plant Physiol 54(3): 287-301.

9. Winkel SB (2001) Flavonoid biosynthesis, a colourful model for genetics, biochemistry, cell biology and biotechnology. Plant Physiol 126(2): 485493.

10. Xu Z, Zhou G, Shimizu H (2010) Plant responses to drought and rewatering. Plant Signal Behav 5(6): 649-654.

11. Larson RA (1988) The antioxidants of higher plants. Phytochemistry 27(4): 969-978.

12. Wang DH, Du F, Liu HY, Liang ZS (2010) Drought stress increases iridoid glycosides biosynthesis in the roots of Scrophularia ningpoensis seedlings. J Med Plants Res 4(24): 2691-2699.

13. Szabo B, Tyihak E, Szabo LG, Botz L (2003) Mycotoxin and drought stress induced change of alkaloid content of Papaver somniferum plantlets. Acta Bot Hung 45: 409-417.

14. Hodaeia M, Rahimmaleka M, Arzania A, Talebi M (2018) The effect of water stress on phytochemical accumulation, bioactive compounds and expression of key genes involved in flavonoid biosynthesis in Chrysanthemum morifolium L. Industrial Crops \& Products 120: 295304.

15. Noguees S, Allen DJ, Morison JIL, Baker NR (1998) Ultraviolet-B radiation effects on water relations, leaf development and photosynthesis in droughted pea plants. Plant Physiol 117(1): 173-181.

16. Soliz GJB, de Rodriguez DJ, Rodriguez GR, Angulo SJL, Mendez PG (2002) Quinoasaponins: concentration and composition analysis. In: Janick J, Whipkey A (Eds.), Trends in new crops and new uses. ASHS, Alexandria, Egypt, pp. 110-114.

17. Jaafar HZ, Ibrahim MH, Fakri NFM (2012) Impact of soil field water capacity on secondary metabolites, phenylalanine ammonialyase (PAL), malondialdehyde (MDA) and photosynthetic responses of Malaysian kacipfatimah (Labisiapumila Benth). Molecules 17: 7305-7322.

18. Nowak M, Manderscheid R, Weigel HJ, Kleinwachter M Selmar D (2010) Drought stress increases the accumulation of monoterpenes in sage (Salvia officinalis), an effect that is compensated by elevated carbon dioxide concentration. J Appl Bot Food Qual 83: 133-136.

19. Bettaieb I, Zakhama N, Wannes W Aidi, Kchouk ME, Marzouk B (2009) Water deficit effects on Salvia officinalis fatty acids and essential oils composition. Sci Horticul 120(2): 271-275.

20.Golkar P, Taghizadeh M (2018) In vitro evaluation of phenolic and osmolite compounds, ionic content, and antioxidant activity in safflower (Carthamus tinctorius L.) under salinity stress. Plant Cell, Tissue and Organ Culture (in press).

21. Tari I, Kiss G, Deer AK, Csiszar J, Erdei L, Galle A (2010) Salicylic acid increased aldose reductase activity and sorbitol accumulation in tomato plants under salt stress. Biol Plant 54(4): 677-683.

22. Krishnamurthy R, Bhagwat KAM (1989) Polyamines as modulators of salt tolerance in rice cultivars. Plant Physiol 91(2): 500-504.

23. Hummel I, EI-Amrani A, Gouesbet G, Hennion F, Couee I (2004) Involvement of polyamines in the interacting effects of low temperature and mineral supply on Pringlea antiscorbutica (Kerguelen cabbage) seedlings. J Exp Bot 55(399): 1125-1134.

24. Molmann JAB, Steindal ALH, Bengtsson GB, Seljasen R, Lea P, et al. (2015) Effects of temperature and photoperiod on sensory quality and contents of glucosinolates, flavonols and vitamin $\mathrm{C}$ in broccoli florets. Food Chem 172: 47-55.

25. Morison JIL, Lawlor DW (1999) Interactions between increasing CO concentration and temperature on plant growth. Plant Cell Environ 22(6): 659-682.

26. Havkin-Frenkel D, Podstolski A, Knorr D (1996) Effect of light on vanillin precursors formation by in vitro cultures of Vanilla planifolia. Plant Cell Tissue Organ Cult 45(2): 133-136.

27. Anasori P, Asghari G (2008) Zingiber officinale. Rosc Res Pharm Sci 3: 59-63.

28. Liu L, Dennis C, Gitz III, Jerry W McClure (1995) Effects of UV-B on flavonoids, ferulic acid, growth and photosynthesis in barley primary leaves. Physiol Plant 93(4): 725-733.

29. Singh S, Sinha S (2005) Accumulation of metals and its effects in Brassica juncea (L) Czern (cv Rohini) grown on various amendments of tannery waste. Ecotoxicol Environ Saf 62(1): 118-127.

30. Thimmaraju BN, Ravishankar GA (2004) In situ and ex situ adsorption and recovery of betalains from hairy root cultures of Beta vulgaris. Biotechnol 20: 777-785.

31. Saba PD, Iqbal M, Srivastava PS (2000) Effect of $\mathrm{ZnSO}_{4}$ and $\mathrm{CuSO}_{4}$ on regeneration and lepidine content in Lepidium sativum. Biol Plant 43(2): 253-256.

32. Sharma RK, Agrawal M, Agrawal SB (2010) Physiological, biochemical and growth responses of lady's finger (Abelmoschus esculentus L.) plants as affected by Cd contaminated soil. Bulletin of Environmental Contamination and Toxicology 84(6): 765-770.

33. Hawrylak B, Matraszek R, Szymanska M (2007) Response of lettuce (Lactuca sativa $L$.) to selenium in nutrient solution contaminated with nickel. Veg Crop Res Bull 67(1): 63-70. 
34. Trejo TG, Jimenez AA, Rodriguez MM, De Jesus SA, Gutierrez LG (2001) Influence of cobalt and other microelements on the production of betalains and the growth of suspension cultures of Beta vulgaris. Plant Cell Tissue Organ Cult 67(1): 19-23.

35. Sharma P, Jha AB, Dubey RS, Pessarakli M (2012) Reactive oxygen species, oxidative damage, and antioxidative defence mechanism in plants under stressful conditions. Journal of Botany 2012: 1-26.

36. Rastgoo L, Alemzadeh A, Afsharifar A (2011) Isolation of two novel isoforms encoding zinc- and copper-transporting P1BATPase from Gouan (Aeluropus littoralis), Plant Omics Journal 4(7): 377-383.

37. Ashraf M (1997) Changes in soluble carbohydrates and soluble proteins in three arid-zone grass species under salt stress. Trop Agric 74: 234237.
38. Janska A, Marsik P, Zelenkova S, Ovesna J (2010) Cold stress and acclimation-what is important for metabolic adjustment? Plant Biol 12(3): 395-405

39. Griffith M, Yaish MWF (2004) Antifreeze proteins in overwintering plants: a tale of two activities. Trends Plant Sci 9(8): 399-405.

40. Nadeau P, Delaney S, Chouinard L (1987) Effects of cold hardening on the regulation of polyamine levels in wheat (Triticum aestivum L.) and alfalfa (Medicago sativa L.). Plant Physiol 8(1): 73-77.

41. Yu B, Liu Y, Pan Y, Liu J, Wang H, et al. (2018) Light enhanced the biosynthesis of terpenoid indole alkaloids to meet the opening of cotyledons in process of photomorphogenesis of Catharanthus roseus. Plant Growth Regulation 84(3): 617-626. (c) (1) Creative Commons Attribution 4.0

For possible submissions Click Here

\section{Submit Article}

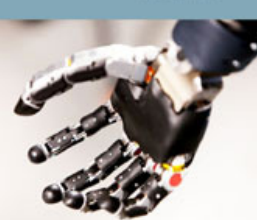

- High-level peer review and editorial services

- Freely accessible online immediately upon publication

- Authors retain the copyright to their work

- Licensing it under a Creative Commons license

- Visibility through different online platforms 